\title{
THEMA
}

\section{Percepção da Avaliação no Ensino Médio Politécnico em uma Escola Da Rede Estadual de Ensino do Rio Grande do Sul}

\section{Evaluation Perception of a High School Polytechnic Education on a School of the Rio Grande do Sul State}

Elisane Ortiz de Tunes Pinto ${ }^{1}$; Marcos André Betemps Vaz da Silva ${ }^{1}$; Valesca de Matos Duarte2; Cristina de Souza Dutra3; Ilis Angela Wickboldt Manetti ${ }^{4}$

\section{RESUMO}

No Estado do Rio Grande do Sul foi implantado o Ensino Médio Politécnico por parte do governo do RS no ano de 2012. Neste relato apresenta-se uma análise sobre a forma como ocorreu o processo de apropriação sobre a avaliação do ensino politécnico na escola, bem como investigou-se os instrumentos e metodologias adotadas. Procurou-se verificar como se deu a atuação docente, no que se refere às atribuições de conceitos por áreas de conhecimento e se o sistema de avaliação por conceitos e pareceres representa ou não avanço no processo de ensino e aprendizagem para os professores. Para análise dos resultados foi utilizada a metodologia do Discurso do Sujeito Coletivo (DSC) e percebeu-se que a implantação do Ensino Médio Politécnico trouxe muitos avanços para o desenvolvimento das atividades de ensino, entretanto, o processo de formação continuada dos professores não ocorreu de forma adequada e vários outros discursos surgiram de forma a qualificar os resultados deste relato.

Palavras-chave: Avaliação da Aprendizagem; Ensino Médio Politécnico; Formação Continuada.

\begin{abstract}
Polytechnic High School was implemented by the government in the state of Rio Grande do Sul at 2012. This report presents an analysis of the way the appropriation process occurred on the evaluation of polytechnic education in the school, as well as how the instruments and methodologies adopted were applied. It was sought to verify how the teaching performance occurred, regarding the attributions of concepts by areas of knowledge and if the system of evaluation by concepts and opinions represents or not progress in the process of teaching and learning for teachers. In order to analyze the results, the methodology of the Collective Subject Discourse (DSC) was used and it was noticed that the implementation of Polytechnic High School brought many advances for the development of teaching activities, however, the process of continuous teacher training did not occur and several other discourses emerged in order to qualify the results of this report.
\end{abstract}

Keywords: Learning Evaluation; Polytechnic High School; Continuous Teacher Training.

\footnotetext{
${ }^{1}$ IFSul - Instituto Federal de Educação, Ciência e Tecnologia Sul-rio-grandense, Pelotas/RS - Brasil.

2 Escola Estadual de Ensino Médio Dr. Carlos Mesko, Canguçu/RS - Brasil.

$35^{\circ}$ Coordenadorias Regional de Educação, Pelotas/RS - Brasil.

${ }^{4}$ Escola Municipal de Ensino Fundamental Antenor Elias de Mattos, Piratini/RS - Brasil.
} 


\section{INTRODUÇÃO}

A partir de pesquisas realizadas em portais de busca, de artigos e teses publicados nos últimos dez anos, percebemos que o tema Avaliação é amplamente estudado gerando muitas produções científicas. Encontramos, no Google acadêmico, com a palavra-chave Avaliação 2.230.000 trabalhos, refinando a busca com Avaliação da aprendizagem escolar 624.000 trabalhos e ainda Avaliação no Ensino Médio 14.700 trabalhos e no Ensino Médio Politécnico 8.500 trabalhos. Já no Portal da Capes com a palavra-chave Avaliação 31.416 trabalhos, Avaliação da aprendizagem escolar 299 trabalhos, Avaliação no Ensino Médio 232 trabalhos e Ensino Médio Politécnico 15 trabalhos. Após análise dos 15 trabalhos referentes ao Ensino Médio Politécnico, observamos que são poucos os estudos publicados neste portal que focalizam a questão da Avaliação da aprendizagem no Ensino Médio Politécnico, destacando o trabalho de Bedin \& Del Pino, que vem contribuir com a presente pesquisa:

Ressalta-se que uma mudança que se restrinja apenas às discussões a respeito do ato pedagógico não se torna eficiente nesta questão, pois as práticas pedagógicas enraizadas na avaliação como método de "acerto de contas" estão presentes nas diversas escolas brasileiras e tal fato se deve à resistência, à alienação e à ingenuidade de docentes ao julgar que suas técnicas avaliativas podem, de alguma forma, qualificar os processos de ensino e aprendizagem. (BEDIN \& DEL PINO, 2015, p.339).

A discussão sobre a avaliação do rendimento escolar não é algo inédito, muito se tem escrito sobre esta modalidade de avaliação nos últimos anos e, percebemos, pela vivência nas escolas onde atuamos, que este assunto está sempre em pauta nas reuniões de conselho de classe nas escolas. Um razoável número de professores ainda tem muitas dúvidas e resistência em assumir uma nova postura frente a avaliação, pois ainda ensinam seus alunos como foram ensinados no passado, de forma tradicional, com repasse de informações, tendo a avaliação quantitativa como a principal forma de determinar se o aluno aprendeu ou memorizou o conteúdo. Para Nogueira, "nosso sistema educacional ainda possui uma cultura muito arraigada, principalmente no que se refere à avaliação, portanto romper com estes paradigmas não é tarefa simples e fácil" (NOGUEIRA, 2001, p.166). Esta concepção de avaliação é histórica, assim como ressalta Romão:

Com uma concepção educacional "bancária" desenvolvemos uma avaliação "bancária" da aprendizagem, numa espécie de capitalismo ás avessas, pois fazemos um depósito de "conhecimentos" e os exigimos de volta, sem juros e sem correção monetária, uma vez que 0 aluno não pode a ele acrescentar nada de sua própria elaboração gnoseológica, apenas repetindo o que lhe foi transmitido. (...) Ao contrário na escola cidadã, na qual se desenvolve uma educação libertadora, o conhecimento não é uma estrutura gnoseológica estática, mas um processo de descoberta coletiva, mediatizada pelo diálogo entre educador e educando (ROMÃO, 2002, p. 48).

Não raro, vivenciamos nas escolas o paradoxo entre a concepção de avaliação e a forma que devemos avaliar. Por um lado, professores ávidos por mudanças devido a compreensão de que avaliação é mais do que uma nota ao final de uma etapa. De outro lado o sistema que exige uma nota justamente ao final desta etapa. Neste caso, os professores que entendem a avaliação como um processo e não um fim precisam estudar formas de propor uma avaliação mais justa, dentro de suas concepções, que avalie de fato a aprendizagem e que, ao mesmo tempo, tenha um registro ao término da etapa avaliativa. 
Entre o ideal e o real está o professor que, por consequência, fica perdido em meio às discordâncias do processo educacional, que lhe obriga a dar uma nota para o aluno, muitas vezes indo contra a sua concepção de educação.

Sabemos que é difícil saltar de um sistema formal de avaliação quantitativa, que mensura o quanto foi aprendido, para um sistema de verificações qualitativas, naturais e voltadas a aprendizagem e ao desenvolvimento. A creditamos que embora pareça utópico, é uma questão de "vontade", que depende do iniciar e do tentar, antes mesmo de predizer sua impossibilidade. (NOGUEIRA, 2001, p. 165)

A avaliação do rendimento escolar não pode ser considerada uma forma de acerto de contas do professor com o aluno, pois assim como nos aponta Moreto, "a avaliação da aprendizagem é um momento privilegiado de estudos, e não um acerto de contas" (MORETO, 2010, p.119). Precisamos vencer esta concepção de avaliação e investir na busca de uma educação de qualidade, buscando avaliar como um todo e não somente medindo conhecimentos. Pensar a avaliação como um processo contínuo, durante todo o ano letivo, proporciona o desenvolvimento integral do aluno, através de atividades que valorizem as suas habilidades em diversas formas e critérios de avaliação, oportunizando um parecer justo e completo.

Segundo Santiago

A avaliação escolar assume a função de um processo abrangente, cuja ênfase deve recair, não só na aprendizagem do aluno, mas também concomitantemente, na organização do ensino e nas relações que se estabelecem na sala de aula. Configurase, desta forma, como um processo de diagnóstico e permanente (SANTIAGO, 2000, p.76).

Partindo desses pressupostos o presente trabalho visa a discussão sobre a avaliação no Ensino Médio Politécnico (EMP). Apontamos o tema como relevante devido a sua grande influência no processo de ensino e aprendizagem no estado do Rio Grande do Sul.

Esta pesquisa foi desenvolvida na disciplina de Processos Avaliativos no Programa de Mestrado Profissional, com o objetivo de analisar diversas formas de avaliações de rendimento escolar, pois entendemos como relevante tal discussão que, embora não seja nova, é sempre atual. Em particular, a essência deste relato foi a implementação e o processo de avaliação no Ensino Médio Politécnico no período de 2012 a 2014 desenvolvido no Ensino Médio Politécnico em uma Escola Estadual de Ensino Médio, localizada na zona rural do município de Canguçu/RS.

Os sujeitos colaboradores desta pesquisa são docentes das áreas de Matemática, Linguagens, Ciências Humanas e Ciências da Natureza, sendo um de cada área do conhecimento, além da vice-diretora e coordenadora pedagógica, totalizando um universo de seis sujeitos que participaram do processo de implantação.

O trabalho teve por objetivos: a) Investigar como ocorreu o processo de apropriação sobre a avaliação do ensino politécnico na escola (reuniões, estudo dos documentos, discussões, leituras, etc.); b) Analisar como acontece a avaliação na escola considerando instrumentos e metodologias adotadas; c) Verificar como a área de atuação de cada docente, atribui os conceitos por áreas de conhecimento; d) Averiguar se o sistema de avaliação por conceitos e pareceres representa ou não avanço no processo de ensino e aprendizagem para os professores. 


\section{METODOLOGIA}

Foi adotada, para o desenvolvimento da investigação, a metodologia qualitativa, pois a mesma é uma das mais utilizadas na área educacional, conforme Triviños "o ensino sempre se caracterizou pelo destaque de sua realidade qualitativa" (TRIVIÑOS, 1987, p. 116).

Em um primeiro momento realizamos a revisão da literatura e exploramos a legislação vigente. Na sequência aplicamos questionários com perguntas abertas aos sujeitos colaboradores da pesquisa a fim de coletar depoimentos acerca do processo avaliativo no Ensino Médio Politécnico (EMP).

As análises dos depoimentos foram realizadas com base na metodologia do Discurso do Sujeito Coletivo (DSC) de Lefèvre e Lefèvre:

O DSC como técnica de processamento de dados com vistas à obtenção do pensamento coletivo dá como resultado um painel de discursos de sujeitos coletivos, enunciados na primeira pessoa do singular, justamente para sugerir uma pessoa coletiva falando como se fosse um sujeito individual de discurso (LEFĖVRE e LEFĖVRE, 2005, p.32).

A técnica do DSC consiste em criar discursos-síntese utilizando a primeira pessoa do singular e desta forma, dar voz a todos os sujeitos envolvidos na pesquisa, representando suas ideias.

O DSC é, assim, uma estratégia metodológica que, utilizando uma estratégia discursiva, visa tornar mais clara uma dada representação social, bem como o conjunto das representações que conforma um dado imaginário (LEFĖVRE e LEFÈVRE, 2005, p. 19).

Para extrair os discursos de forma que o pesquisador não interfira com interpretações e respeite as ideias dos entrevistados, é necessário utilizar figuras metodológicas que proporcionam fidedignidade e assim, representar a ideia de todos os sujeitos. Estas figuras são as Expressões Chaves que são os trechos que apresentam sentido semelhantes; as Ideias Centrais que são o sentido de cada discurso que apresentam tema comum. A partir daí realiza-se as ancoragens que são as teorias que fundamentam os discursos e que dão sustentabilidade ao sentido.

\section{AVALIAÇÃO, EMP E A LEGISLAÇÃO VIGENTE}

A avaliação, por ser amplamente debatida e alvo de inúmeras pesquisas e publicações, conta com várias definições desde as mais tradicionais que a consideram como aferição resultados meramente quantitativos até os conceitos mais atuais onde compreendem a avaliação como um processo e não um fim.

Consideramos uma compilação de conceitos sobre avaliação, na visão de diferentes autores através da obra de José Eustáquio Romão (2011), por entendermos que é fundamental contextualizar a avaliação numa perspectiva de distintas visões:

Avaliação é o processo de atribuição de símbolos a fenômenos com o objetivo de caracterizar o valor do fenômeno, geralmente com referência a algum padrão de natureza social, cultural ou científica. (BRADFIELD e MOREDOCK, 1963, 1: 16);

Avaliar é julgar ou fazer a apreciação de alguém ou alguma coisa, tendo como base uma escala de valores [ou]interpretar dados quantitativos e qualitativos para obter 
um parecer ou julgamento de valor, tendo por base padrões ou critérios. (HAYDT, 1988: 10).

O conceito de avaliação da aprendizagem que tradicionalmente tem como alvo o julgamento e a classificação do aluno necessita ser redirecionado $(. .).(. .$.$) desponta$ como finalidade principal da avaliação o fornecer sobre o processo pedagógico informações que permitam aos agentes escolares decidir sobre intervenções e redirecionamentos que se fizerem necessários em face do projeto educativo definido coletivamente e comprometido com a garantia da aprendizagem do aluno. (SOUSA, 1993: 46).

A avaliação consistirá em estabelecer uma comparação do que foi alcançado com o que se pretende atingir. Estaremos avaliando quando estivermos examinando o que queremos, o que estamos construindo e o que conseguimos, analisando sua validade e eficiência (= máxima produção com um mínimo de esforço). (SANT'ANNA, 1995, 23-4)

[A avaliação é] um juízo de qualidade sobre dados relevantes para uma tomada de decisão. (LUCKESI, 1995: nota 6, p. 9).

Conforme observamos, há diversos conceitos assim como há diversas opiniões e compreensão sobre o que é avaliação, o que é avaliar e qual deve ser a melhor maneira e mais justa de avaliarmos nossos alunos. Sabemos que conceitos e entendimentos acerca deste processo se dão, também, a partir das concepções que temos de educação. E, para além de nossas concepções enquanto educadores, temos a legislação que nos dá orientação para que possamos realizar nosso trabalho dentro das normas.

A Lei de Diretrizes e Bases da Educação Nacional (LDB 9394/96) confere caráter de norma legal à condição do Ensino Médio como parte da Educação Básica, quando, por meio do artigo 21, estabelece que a Educação básica é formada pela Educação Infantil, Ensino Fundamental e Ensino Médio.

A LDB, no seu Artigo 24, em seu inciso V preconiza:

V - a verificação do rendimento escolar observará os seguintes critérios:

a) avaliação contínua e cumulativa do desempenho do aluno, com prevalência dos aspectos qualitativos sobre os quantitativos e dos resultados ao longo do período sobre os de eventuais provas finais;

b) possibilidade de aceleração de estudos para alunos com atraso escolar;

c) possibilidade de avanço nos cursos e nas séries mediante verificação do aprendizado;

d) aproveitamento de estudos concluídos com êxito;

e) obrigatoriedade de estudos de recuperação, de preferência paralelos ao período letivo, para os casos de baixo rendimento escolar, a serem disciplinados pelas instituições de ensino em seus regimentos;

Conforme podemos observar a LDB trata a avaliação de maneira processual com a prevalência dos aspectos qualitativos.

No ano de 2014 foi sancionada a lei 13.005 que aprova o Plano Nacional de Educação (PNE) que aponta metas e estratégias. Entre elas a meta 7 que tem como objetivo "fomentar a qualidade da educação básica em todas as etapas e modalidades, com melhoria do fluxo escolar e da aprendizagem e índice do IDEB". Esta meta traz as seguintes estratégias:

- induzir processo contínuo de autoavaliação das escolas de educação básica, por meio da constituição de instrumentos de avaliação que orientem as dimensões a serem fortalecidas, destacando-se a elaboração de planejamento estratégico, a melhoria 
contínua da qualidade educacional, a formação continuada dos (as) profissionais da educação e o aprimoramento da gestão democrática;

- aprimorar continuamente os instrumentos de avaliação da qualidade do ensino fundamental e médio, de forma a englobar o ensino de ciências nos exames aplicados nos anos finais do ensino fundamental, e incorporar o Exame Nacional do Ensino Médio, assegurada a sua universalização, ao sistema de avaliação da educação básica, bem como apoiar o uso dos resultados das avaliações nacionais pelas escolas e redes de ensino para a melhoria de seus processos e práticas pedagógicas;

- desenvolver indicadores específicos de avaliação da qualidade da educação especial, bem como da qualidade da educação bilíngue para surdos;

- melhorar o desempenho dos alunos da educação básica nas avaliações da aprendizagem no Programa Internacional de Avaliação de Estudantes - PISA.

Fica evidente o interesse em uma avaliação de qualidade, assim como preconiza a LDB, e um fator importante é o que nos aponta uma das estratégias da meta 7 que salienta a formação continuada dos profissionais da educação. Entendemos como fundamental, haja vista que, toda e qualquer melhoria e mudanças na educação necessita da formação dos profissionais sob pena das propostas chegarem às escolas como imposição, ferindo o processo democrático.

Segundo o Parecer número 310 de 2012, do Conselho Estadual de Educação, que aprova o Regimento Escolar Padrão para o Ensino Médio Politécnico, "a avaliação é emancipatória caracterizando-se como um processo e a possibilidade do vir a ser, da construção de cada um e do coletivo de modo diferente".

A avaliação tem as seguintes funções (Parecer 310/2012):

- Diagnóstica: favorecendo o planejamento, organiza o trabalho do professor, oportunizando novas estratégias e alternativas, assim como possibilita ao aluno verificar seu nível de conhecimento;

- Formativa: destinando-se a informar a situação em que se encontra o aluno, no que se refere ao desenvolvimento de suas aprendizagens. Contempla a auto-avaliação do aluno, do grupo, da turma e dos educadores;

- Contínua e cumulativa: considerando a construção do conhecimento do aluno, como um todo, coerente e significativo. Apresenta situações de construção de conhecimento de forma crescente em complexidade, tendo como parâmetro as construções do próprio aluno.

Também segundo o Parecer 310/2012 "o processo avaliativo se dará em dois momentos: nas disciplinas, a partir do espaço da sala de aula pela interação entre componentes curriculares e áreas do conhecimento, e no projeto vivencial, no componente Seminário Integrado a partir do planejamento, execução e avaliação do mesmo".

A expressão dos resultados no Ensino Médio Politécnico "informa o desenvolvimento da aprendizagem do aluno, que se dará de forma contínua e sistemática", ao findar o trimestre e/ou ano letivo, terá a seguinte formulação (Parecer 310/2012):

- Construção Satisfatória da Aprendizagem (CSA): expressa a construção de conceitos necessários para o desenvolvimento dos processos da aprendizagem, correspondentes ao ano de escolarização, embasados na apropriação dos princípios básicos das áreas do conhecimento, desenvolvidos na formação geral e na parte diversificada, ambas relacionadas no Plano de Trabalho do Professor. É atribuída trimestralmente e ao final do ano letivo, tem caráter cumulativo e sumativo e sinaliza a aprovação e o avanço do aluno para o ano subsequente de sua escolarização para 0 ano letivo seguinte. $O$ aluno com CSA conclui o ano letivo com aprovação. 
- Construção Parcial da Aprendizagem (CPA): expressa a construção parcial de conceitos necessários para a construção das aprendizagens, correspondentes ao ano de escolarização, embasados na apropriação dos princípios básicos das áreas do conhecimento, desenvolvidos na formação geral e na parte diversificada, ambas relacionadas no Plano de Trabalho do Professor. É atribuída trimestralmente ou ao final do ano letivo, tendo caráter cumulativo e sumativo. O aluno com CPA durante os trimestres realiza estudos de recuperação por meio do PPDA (Projeto Político Pedagógico de Apoio), que é um instrumento norteador dos estudos de recuperação, cabendo ao Conselho de Classe analisar seu desempenho. Constatada a construção dos conceitos necessários para o desenvolvimento dos processos cognitivos e a superação da Construção Parcial da Aprendizagem, deverá ser alterada a expressão do resultado anterior. Ao final do $1^{0}$ e $2^{\circ}$ Anos do curso o aluno é aprovado para o ano seguinte com indicativo no PPDA. Ao final do $3^{0}$ Ano o aluno é aprovado, considerando que a CPA não é impeditiva para que o aluno construa suas aprendizagens em outros tempos e espaços.

- Construção Restrita da Aprendizagem (CRA): expressa a construção restrita dos conceitos necessários para a construção das aprendizagens, correspondentes ao ano de escolarização, embasados na apropriação dos princípios básicos das áreas do conhecimento, desenvolvidos na formação geral e na parte diversificada, ambas relacionadas no Plano de Trabalho do Professor. É atribuída trimestralmente e ao final do ano letivo, tem caráter cumulativo e somativo. O aluno com CRA durante os trimestres realiza estudos de recuperação por meio do PPDA (Projeto Político Pedagógico de Apoio), que é um instrumento norteador dos estudos de recuperação, cabendo ao Conselho de Classe analisar seu desempenho. Constatada a construção dos conceitos necessários para o desenvolvimento dos processos cognitivos e a superação da Construção Restrita da Aprendizagem, deverá ser alterada a expressão do resultado anterior. Ao final do $1^{\circ}$ e $2^{\circ}$ Anos do curso como conceito final (CRA) em uma área do conhecimento, após os estudos de recuperação (PPDA) e exames finais (entre períodos), o aluno avança para o ano seguinte com Progressão Parcial. Ao final do $3^{\circ}$ Ano do curso, como conceito final em uma área do conhecimento, aluno poderá optar por realizar os Estudos Prolongados de Recuperação ou cursar o $3^{\circ} \mathrm{Ano}$ do ensino médio. Ao final do ano letivo $\left(1^{0}, 2^{0}\right.$ ou $\left.3^{\circ}\right)$ o aluno com conceito final restrito em mais de uma área do conhecimento, após os estudos de recuperação e exames finais, é considerado reprovado.

O processo de avaliação na proposta do Ensino Médio Politécnico está fundamentado na concepção da Avaliação Emancipatória de Ana Maria Saul, e considera "A avaliação emancipatória apresenta dois objetivos básicos: iluminar o caminho da transformação e beneficiar as audiências no sentido de torná-las autodeterminadas" (SAUL, 1995, p. 91).

Nesta perspectiva, observamos que a legislação vigente preconiza a avaliação como processual, levando em conta outros aspectos, que não somente os inerentes ao momento de avaliação e aos momentos da sala de aula. Entretanto, compreendemos que muitas vezes a legislação nos apresenta uma estrutura e uma proposta e que na aplicação desta legislação surgem as interpretações e as atuações de cada docente.

\section{RESULTADOS E DISCUSSÕES}

Conforme apresentado na Metodologia, foi utilizada a técnica do DSC para a coleta e análise dos dados. Aqui apresentamos os resultados a partir dos depoimentos dos sujeitos colaboradores deste trabalho sobre a avaliação no EMP, bem como a formação que os mesmos receberam para as mudanças que eram acenadas pelo governo. 
Primeiramente analisamos os depoimentos de quatro docentes de uma Escola Estadual de Ensino Médio, situada no município de Canguçu RS, sendo um de cada área do conhecimento a saber: Matemática, Linguagens, Ciências da Natureza e Ciências Humanas.

As respostas às cinco perguntas acerca da implantação do EMP e sobre as mudanças no sistema de avaliação foram analisadas à luz do DSC, o que gerou alguns discursos-síntese representando a ideia da coletividade colaboradora deste trabalho.

As questões apresentadas que configuram-se em Instrumentos de Análise do Discurso (IAD) foram as seguintes:

IAD1 - Relate como ocorreu o processo de apropriação sobre a avaliação do ensino politécnico na escola (reuniões, estudo dos documentos, discussões, leituras, etc.)

IAD2 - Como ocorre a avaliação na sua escola considerando instrumentos e metodologias adotadas?

IAD3 - Considerando que são atribuídos conceitos (CSA, CPA, CRA) por áreas de conhecimento, explique como a sua área atribui estes conceitos aos alunos.

IAD4 - Na sua opinião, o sistema de avaliação por conceitos e pareceres representa ou não avanço no processo de ensino e aprendizagem? Explica.

IAD5 - Você considera que a avaliação desenvolvida na sua escola contempla uma avaliação diagnóstica, formativa, contínua e cumulativa? Justifique.

Quanto ao processo de apropriação sobre a avaliação do EMP fica evidente no primeiro discurso o qual se refere à estratégia e plano de ação adotada pela gestão, que houve alguns encontros, mas que estes não foram suficientes para que de fato ocorresse uma formação docente. O discurso aponta que a equipe diretiva participou de formação oferecida pela SEDUC, mas que esta não supriu as expectativas haja vista as dúvidas que pulsavam quanto ao novo processo. A partir daí, a direção realizou reunião no início do ano letivo a fim de repassar aos professores alguns pontos básicos e os documentos foram disponibilizados na sala dos professores.

\section{DSC1: Estratégia - Plano de ação}

Em 2012 quando foi implantado o EMP, a escola que eu lecionava realizou encontros para discutir como seria a melhor estratégia de organizar um plano de ação, tendo em vista que a SE não havia previsto as possíveis indagações quanto ao desenvolvimento da chamada "disciplina do Seminário Integrado", mas como a escola já trabalhava na ótica de realização de projetos interdisciplinares, a transição foi tranquila. A equipe diretiva à época, fevereiro de 2012, participou de uma formação promovida pela SEDUC que deveria ser de orientação e esclarecimento sobre o EMP, o que não supriu as expectativas. Após, houve uma reunião geral na escola, no início do ano letivo, em que foi passado aos professores alguns pontos básicos. Foram disponibilizadas cópias dos documentos regulamentadores do EMP na sala dos professores para que os docentes tivessem acesso. Nos reunimos algumas poucas vezes na escola.

A formação docente é um ponto bem debatido entre educadores e, para além da formação oficial que os professores possuem, voltamo-nos à importância da formação continuada inclusive com reuniões pedagógicas regulares na própria instituição de ensino. 
O seguinte discurso nos mostra esta necessidade:

\section{DSC2: Tempo para estudos}

Discutimos as mudanças entre os colegas, mas foram poucas as oportunidades de estudo e debate até mesmo porque não existe tempo para isso nas escolas. No primeiro ano ocorreram algumas reuniões pedagógicas, no segundo em 2013 ocorreram mensalmente, nos anos seguintes vendo a exaustão dos professores para dar conta das exigências do processo como um todo a equipe diretiva passou a aproveitar o tempo das horas atividades dos professores, além de outros momentos para que o diálogo ocorresse durante o horário de trabalho.

Os docentes possuem seus conhecimentos constituídos no seu fazer pedagógico, mas é fundamental que estes fazeres e estes saberes possam ser compartilhados.

Tardif aponta que para os professores,

[...] sua integração e sua participação na vida cotidiana da escola e dos colegas de trabalho colocam igualmente em evidência conhecimentos e maneiras de ser coletivos, assim como diversos conhecimentos do trabalho partilhados entre os pares, notadamente a respeito dos alunos e dos pais, mas também no que se refere a atividades pedagógicas, material didático, programas de ensino, etc. (TARDIF, 2014, p. 61).

Neste sentido, quando surge um novo programa de governo, como o EMP, mais importante se torna este momento de partilha de saberes, discussões pedagógicas, ou seja, a formação dos educadores, pois em cada mudança de programa proposta por um governo, observamos certa resistência por parte da maioria dos docentes e isso pode ser observado a partir da análise do próximo discurso acerca deste processo.

\section{DSC3: Resistência}

Vale lembrar que a categoria iniciou uma grande resistência à nova proposta, pois foi simplesmente imposição. O processo de implantação do EMP, pelo que observei, foi tenso e incerto nas escolas. Angustiante para equipe diretiva, professores e mais tarde para aos alunos, justamente pelo processo de avaliação e suas menções. Houve a tentativa de acalmá-los, de que iríamos nos adaptando aos poucos e dentro da nossa realidade. Ficou decidido que, embora a avaliação seria por pareceres, os professores continuariam utilizando notas em suas avaliações como parâmetro, uma vez que, analisar o aluno como um todo, ir além da nota da prova, observando o desenvolvimento dia a dia do aluno no cumprimento de seus deveres como estudante, já era uma prática da maioria dos professores e finalmente no conselho de classe o grupo discutia sobre alguma eventual dúvida quanto ao desempenho e merecimento do aluno. Em síntese, esta apropriação se deu aos poucos, buscando um consenso na forma de avaliação entre os professores, para não causar ainda mais incertezas e conflitos. A equipe diretiva buscou também explicar aos pais o que significavam as menções e como funcionaria o processo ensino, aprendizagem e avaliação, o que para estes, não foi fácil de compreender.

Voltamos então à formação e a necessidade da construção coletiva para que haja tempo hábil para que todos os envolvidos no processo (professores, pais/responsáveis, alunos) possam obter esclarecimentos e sugerir a partir da proposta. Sem este tempo e com a necessidade de adaptar todas as mudanças em curto prazo, a resistência se instala. Os professores pouco a pouco adaptam suas metodologias, mas com o ano letivo em andamento, o processo se torna mais árduo para todos.

Diante do exposto até o momento, percebemos que, mesmo de maneira tumultuada, com o tempo reduzido para travar um debate proveitoso, o sistema de avaliação sofreu mudanças e ajustes. 
Ao perguntarmos aos professores colaboradores deste trabalho sobre a avaliação na escola, obtemos o seguinte discurso-síntese:

\section{DSC4: Avaliação}

A avaliação é trimestral, cada professor decide como irá fazer o seu processo avaliativo, há muita flexibilidade nisso. Desenvolvem-se trabalhos individuais, em grupos, provas, projetos dentro da disciplina de Seminário Integrado em conjunto com os demais professores que também avaliam os trabalhos apresentados. Acredito que, dentro das nossas possibilidades, procuramos avaliar os nossos alunos considerando os mesmos em sua totalidade, especialmente no que se refere aos aspectos afetivos além dos cognitivos. Isto se dá, através da proposta do trabalho por meio de projetos. A avaliação segue o princípio de buscar, apresentar resultados das habilidades e competências dos alunos, através de pareceres descritivos, considerando os diversos instrumentos de avaliação como provas, trabalhos em grupo, duplas, projetos integrados, trabalhos de pesquisa, apresentações de seminários, etc. Lembrando que, assim como temos muitos limitantes nesta metodologia (recursos materiais, planejamento, engajamento), temos também disciplinas e/ou professores que não se adaptam a este tipo de processo de ensino/aprendizagem.

A avaliação ocorrendo de forma flexível, ou seja, sem imposição da gestão, proporciona aos professores liberdade para elaborar seus instrumentos e sua metodologia de trabalho de acordo com suas concepções de educação, pois a avaliação está intrínseca na ação pedagógica e representa os ideais presentes na prática docente.

Para Saul,

a avaliação, na escola, particularmente na sala de aula, incide sobre práticas educativas $e$, consequentemente, as decisões que precisam ser tomadas sobre métodos, procedimentos e instrumentos de avaliação somente fazem sentido se forem coerentes com essas práticas (SAUL, 2008, p.19).

Para além da flexibilidade acerca dos instrumentos planejados, precisamos também considerar que a proposta de avaliação para o EMP acarreta mudanças que não podem simplesmente serem abordadas como uma conversão de notas aritméticas para conceitos. Há uma mudança crucial na forma de avaliar o aluno no momento que atribuímos conceitos - no EMP: CSA, CPA, CRA -, pois neste caso a avaliação deverá ser realizada por áreas do conhecimento e não mais o professor isoladamente com sua disciplina. A partir desta mudança, os docentes relataram sobre como as áreas atribuem estes conceitos gerando os seguintes DSC's:

\section{DSC5: Educação Integral}

A construção do conhecimento é tida como um todo, sendo assim, procura-se coesão quanto aos objetivos propostos que apontam as dificuldades apresentadas. Embora tenha agregado nos anos de docência uma visão mais integral do desenvolvimento do aluno, buscando flexionar os instrumentos de avaliação de acordo com as realidades encontradas nas turmas, bem como fechar um conceito analisando como foi o empenho, a dedicação, enfim o comprometimento do aluno.

\section{DSC6: Avaliação Tradicional/Bom Senso}

O aluno atingindo sessenta por cento é considerado aprovado. É consenso que o aluno precisa novas estratégias de avaliação, mas na realidade, o que costuma-se observar é a realização de instrumentos de avaliação já realizados, porém com novas abordagens. Com as atuais condições de tempo ofertadas por nosso sistema de trabalho, nos organizamos através de planilhas onde cada disciplina preenche os seus resultados e, dentro do possível, debate-se com os colegas de área o conceito atribuído a cada aluno. Não abro mão do que considero um mínimo que o aluno precisa saber para acompanhar o ano seguinte, ou seja, o professor precisa ter sensibilidade e bom senso. 
Em vista dos discursos que apresentamos, podemos observar que o professor ainda requer um tempo maior para realizar seu planejamento e também a avaliação. Sem este tempo os docentes acabam por utilizar estratégias para corresponder uma exigência, mas ainda aquém de uma real avaliação por área do conhecimento que visa o trabalho coletivo e uma avaliação mais processual do que pontual.

Entretanto é importante salientarmos que uma mudança de algo arraigado historicamente requer rupturas de crenças e de um processo que está posto por séculos na educação.

Segundo Romão a avaliação

[...] sempre carrega consigo uma dimensão classificatória, mesmo quando se compara a qualidade do desempenho de alguém ou de uma instituição em momentos diferentes de sua trajetória, sem compará-la com as trajetórias de outrem. Para a verificação de seus avanços em relação às suas situações anteriores, é necessário compará-los a padrões desejáveis e previamente estabelecidos. Portanto, mesmos na sua dimensão diagnóstica, a avaliação apresenta sempre um viés comparativo, classificatório (ROMÃO, 2002, p.45).

Se pensarmos que a discussão sobre processos avaliativos vem sendo abordada e refletida ao longo dos anos, a opinião dos docentes sobre o sistema de avaliação por conceitos e pareceres como propõe o EMP não poderia apresentar outras respostas senão as reflexões que o tema sugere. Devido estas reflexões que o tema avaliação incita, tivemos dois DSC's com ideias distintas sendo o primeiro mostrando o avanço que a avaliação por conceitos e pareceres representa e o segundo a ideia de que não representa avanço real, conforme podemos apreciar a seguir:

\section{DSC7: Representa Avanço}

Particularmente, acredito neste sistema pela possibilidade de avaliar os alunos em todos os aspectos que envolvem o processo de ensino/aprendizagem. Por um lado acho importante porque o aluno desenvolve sua criatividade, a criticidade, apresenta desenvoltura ao expressar sua oralidade. Para o professor e para o aluno comprometido pouco importa se são conceitos, notas, pareceres, etc. O ensino e a aprendizagem vão ocorrer, respeitando-se o tempo e os fatores que interferem no aprendizado de cada aluno. Quero dizer, haverá crescimento, haverá aquisição de conhecimentos, haverá educação para a vida e a cidadania. O principal avanço penso ser o exercício de pensar e fazer diferente, o exercício de desacomodar-se, o exercício da crítica, o exercício da comunicação com os pares, o exercício de flexibilizar, de aceitar as diversas opiniões e pontos de vistas.

\section{DSC8: Não representa Avanço Real}

É um grande paradoxo. É notado que a proposta de propor um diagnóstico do aluno teria tudo para ser um grande avanço. No entanto, os instrumentos de avaliação externa são classificatórios e eliminatórios. O senso comum apenas observa esta circunstância, acho que o aluno não adquire conhecimento básico essencial. As condições de trabalho dos docentes, amplamente debatidas e conhecidas por todos, não oferecem meios para que este sistema possa ser realmente vivenciado e testado na prática do cotidiano escolar. Hoje, do modo como está, representa retrocesso.

O primeiro discurso apresenta uma visão otimista do sistema considerando a educação integral do estudante e a avaliação que tanto discutimos e almejamos. Nos remete a Freire:

O ideal é que, cedo ou tarde, se invente uma forma pela qual os educandos possam participar da avaliação. É que o trabalho do professor é o trabalho do professor com os alunos e não do professor consigo mesmo. 
Esta avaliação crítica da prática vai revelando a necessidade de uma série de virtudes ou qualidades sem as quais não é possível nem ela, a avaliação, nem tampouco o respeito do educando (FREIRE, 1997, p. 71-72).

Em contrapartida o segundo discurso não apresenta uma negação da avaliação não quantitativa, mas traz uma reflexão sobre o modo como está colocada. Os professores no discurso representado, consideram a importância de uma avaliação diagnóstica, mas assim como nos apontou Romão (2002), traz a questão da avaliação externa à escola, as quais os alunos enfrentarão, e que continua classificatória e eliminatória.

Concluindo a análise dos depoimentos dos docentes a última questão diz respeito à avaliação desenvolvida na escola e se a mesma contempla uma avaliação diagnóstica, formativa, contínua e cumulativa ao que obtivemos os seguintes DSC's que, ao exemplo dos anteriores também trazem opiniões distintas.

\section{DSC9: Avaliação Dialógica}

Sim. O diferencial está na proposição pela qual o aluno se vê como sujeito da sua própria história. Sua capacidade de interagir no meio em que vive e conhecer novos horizontes caminham juntos. Penso que algumas disciplinas já atingem esse objetivo apesar de todos os entraves do sistema. Outras, apesar do discurso, apenas iniciam a caminhada.

\section{DSC10: Orientação Pedagógica}

Não, a maioria passa sem atingir os objetivos nas diversas áreas do conhecimento, penso que fica a desejar. $\mathrm{Na}$ escola não há uma atuação continua e eficiente por parte da coordenação escolar (orientação e supervisão), que deveria servir de apoio a alunos e professores, buscando agregar o grupo e planejar novas estratégias para a superação das dificuldades de ambos. Enquanto o professor trabalhar sozinho com seus alunos não iremos avançar nesta direção. Na verdade, penso que poderíamos melhorar muito essa forma de avaliação se contássemos com esse setor ativo de fato, mas atender plenamente os itens elencados vejo como utopia.

É salutar observarmos que a resistência dos docentes não está em avançar nas reflexões acerca da avaliação. Muitos, inclusive, já avançam na direção de uma educação que encara a avaliação como parte do processo e não um fim.

O sistema e suas normas impostas sem as devidas condições e estrutura adequada para travar os debates, sem tempo real para a formação continuada é o que impede para que mais avanços ocorram.

Ainda segundo Freire,

na formação permanente dos professores, o momento fundamental é o da reflexão crítica sobre a prática. É pensando criticamente a prática de hoje ou de ontem que se pode melhorar a próxima prática. O próprio discurso teórico, necessário à reflexão crítica, tem de ser de tal modo concreto que quase se confunda com a prática (FREIRE, 1997, p. 43-44).

Analisando todos os discursos aqui apresentados podemos concluir que os professores clamam por formação continuada, mas sem a imposição de programas que chegam sem aviso prévio. Fato este que reforça o quão importante são as pesquisas como esta que faz uma escuta qualificada e, desta forma, proporciona voz e vez àqueles que estão diariamente frente ao processo pedagógico. 
Os professores almejam uma educação de melhor qualidade e compreendem que a avaliação é um processo que necessita de constante debate e reflexão. Contudo, ainda esbarramos em um sistema rígido, com mudanças impostas e não refletidas que, mesmo que a intenção seja de melhorias na qualidade da educação, não acolhe aqueles que realmente fazem essa mudança - os professores!

Na sequência e utilizando as mesmas perguntas como IAD que foram respondidas pelos docentes, apresentamos a visão da gestão escolar (vice-diretora e coordenadora pedagógica) sobre a implantação do EMP. Em seus discursos, apresentados através do DSC, emergem questões relacionadas às políticas públicas de governo que criam regimentos que interferem em todo o processo educativo, neste caso com alterações relevantes que se referem à avaliação e aos instrumentos avaliativos que foram salientados pelos sujeitos colaboradores que fazem parte da gestão escolar.

O DSC11 surgiu do agrupamento das expressões-chave com ideias centrais relacionadas às políticas públicas de governo, no caso a implantação do EMP, bem como o regimento que o orienta.

\section{DSC11 - Políticas públicas de governo e regimento}

O processo de apropriação sobre avaliação no EMP na escola ocorreu segundo as orientações da SEDUC. A direção reuniu os professores e os colocou a par das orientações em relação ao Ensino Médio Politécnico, sem discussões ou estudo. A CRE enviou um modelo de regimento para a escola o qual foi alterado somente o que se refere aos dados da escola, o que aconteceu foi que os professores tiveram que buscar o entendimento da proposta e se adaptar a ela. Percebemos que a educação é tratada como política de governo e não como política de estado, pois a cada troca de governantes há novas propostas de reestruturações no processo educativo. Na maioria das vezes, as mudanças partem dos gabinetes e cabe à gestão escolar acatar as demandas e viabilizar a forma de cumpri-las, apenas repassando as informações aos docentes.

Para Hofling (2001) ações voltadas para eficiência do ensino e da aprendizagem, da gestão escolar e da utilização dos recursos da educação são insuficientes para a melhoria do processo educativo. Enquanto não houver efetivamente a participação dos envolvidos em todas as esferas educacionais (decisão - planejamento - execução) poderemos ter índices positivos à avaliação de políticas educacionais, mas não à avaliação política da educação.

A avaliação educacional necessita ser vista como um processo integrado que leva em conta seus sujeitos, professores e alunos, como seres de direitos e deveres, participantes ativos e protagonistas do processo de ensino e aprendizagem. O processo avaliativo no EMP deve estar em consonância com as Diretrizes Curriculares Nacionais para o Ensino Médio (DCNEM), que reforçam o compromisso da "avaliação da aprendizagem, com diagnóstico preliminar, e entendida como processo de caráter formativo, permanente e cumulativo" (BRASIL, 2012).

O discurso seguinte, DSC12, apontou questões relacionadas à avaliação e aos instrumentos avaliativos. 


\section{DSC12: Avaliação e Instrumentos Avaliativos}

A avaliação acontece de acordo com o que está no regimento enviado pela SEDUC. Primeiramente, a direção reuniu os professores para passar informações de como seria a avaliação. Para avaliar os estudos os professores teriam que se reunir por área do conhecimento, expor como estas se apresentam no momento nas disciplinas e chegarem a um consenso sobre o aproveitamento e conhecimento destes na área, pontuando as dificuldades e maneiras de superá-las, após, atribuir o conceito e redigir os pareceres que retrate a situação real das atividades dos alunos. Tendo em vista a necessidade de desvincular a avaliação como instrumento classificatório seletivo, os conceitos CSA, CPA, CRA com pareceres descritivos substituíram a nota. Avançamos bastante, mas estamos muito apegados na avaliação classificatória, embora com a implantação do EMP tivemos um ganho significativo no que diz respeito a avaliação diagnóstica, formativa, contínua e cumulativa, temos o que aprender e nos desafiar nesta proposta, que considero ser um avanço para o ensino e aprendizagem. Tendo em vista que devemos avaliar o aluno como um todo e não de forma fracionada, avaliar por conceitos e pareceres me parece um avanço mas nos deparamos com a resistência e falta de preparo dos professores para avaliar o processo Ensino Aprendizagem como um todo. A dificuldade maior está na elaboração de um único parecer por área quando envolve vários professores e estes não dispõe de tempo suficiente para discutirem e elaborarem um único parecer juntos. Os professores usam instrumentos diversificados de acordo com a metodologia aplicada por cada um através de projetos que exigem pesquisa, trabalhos de grupo e apresentações, provas e trabalhos científicos com produção textual.

Entendemos que a avaliação prima pela viabilidade de o aluno perceber seu crescimento em relação as suas aprendizagens nas diferentes áreas do conhecimento e também por saber identificar a aplicabilidade do que foi ensinado cabendo ao professor identificar as dificuldades e potencialidades que por ventura ocorrerem durante esse processo de ensino e aprendizagem.

No Caderno Formação de Professores do Ensino Médio - A Avaliação no Ensino Médio, encontramos uma proposta de avaliação similar a do EMP,

Tal perspectiva de avaliação contrapõe-se ao senso comum de conceber a avaliação como sinônimo de medida, prova, e tendo como função a classificação e hierarquização, consequência de uma concepção que vê a formação e a educação como "bem privado" que deve nos conduzir ao sucesso individual. Seria necessário, portanto, perseguirmos o desafio de tornar senso comum outra noção de avaliação, ou seja, percebê-la como parte integrante dos processos de ensino e aprendizagem, com função diagnóstica, formativa e somativa (BRASIL, 2013, p. 8).

O EMP objetivando a formação integral tem um olhar para a avaliação voltado para a construção da autonomia, da responsabilidade social e do exercício da cidadania, porém durante seu processo de implantação esses aspectos não foram estudados de forma que visassem sua utilização no processo avaliativo, logo percebemos no DSC12 dificuldades em realizar uma avaliação integrada.

Outro fator a ser analisado é o referente aos instrumentos avaliativos que no EMP exigiram profunda mudança de metodologia, mas que não foram instigados e estudados. Sendo assim, inúmeras vezes, a avaliação acabou sendo um mero somatório de notas. Só é possível avaliar, com plenitude, quando temos critérios de avaliação bem definidos e não apenas quantificados.

Raphael salienta que,

a qualidade técnica de um processo avaliativo reside, essencialmente, no aprimoramento dos instrumentos utilizados. Estes instrumentos tem o objetivo de obter dados de medida que formarão um conjunto ao qual será atribuído o juízo de valor. Estes dados que servirão ao julgamento necessitam ter qualidades técnicas para que o juízo seja aceitável (RAPHAEL, 1995, p. 34). 
Para o sucesso da avaliação no EMP seria preciso refletir sobre como ocorrem as interações no processo avaliativo e levar em conta o que os professores sabem sobre a temática antes de mudar metodologias, instrumentos avaliativos e suas representações. $E$, conforme observamos nos depoimentos dos professores a necessidade de refletir sobre as mudanças propostas com tempo para discussão se faz importante e necessária.

O DSC dos gestores vem ao encontro do DSC dos professores onde representa a ideia de que é necessário tempo de estudos para que uma mudança deste porte se efetive com os resultados esperados.

Outra informação interessante que encontramos a partir das análises dos discursos é que tanto os gestores quanto os professores relatam que não houve preparo, estudos e debates a partir das mudanças propostas pelo governo, havendo reuniões para passar informações apenas.

A avaliação, por ser um tema de amplo debate em educação, deve ser exaustivamente estudada e discutida nas escolas, para além dos gabinetes, pois é na escola que ela se efetiva, que pode ser traçado seus pontos positivos e outros a serem reformulados. Neste sentido, por mais que esteja imbuída de boas intenções, nenhuma proposta de mudança na educação, sobretudo em avaliação, poderá alcançar sua plenitude se não for amplamente debatida por aqueles que fazem a educação no dia a dia, ou seja, os professores e também os alunos.

Ao analisarmos por dois vieses (professores e gestores) observamos que independente do cargo ocupado, todos são educadores e comungam de ideias semelhantes quanto se trata de formação continuada e possibilidades de debate antes de qualquer implantação de propostas. É possível também vermos que os educadores não são contra as mudanças e sim como elas ocorrem, se são impostas, sem tempo de reflexões, ocasiona o que poderíamos chamar de desconforto pedagógico.

\section{CONSIDERAÇÕES FINAIS}

Neste trabalho foi apresentada uma análise sobre a forma como ocorreu o processo de apropriação sobre a avaliação do ensino politécnico na escola, bem como os instrumentos e metodologias adotadas. Procurou-se verificar como se deu a atuação docente e se o sistema de avaliação por conceitos e pareceres representa ou não avanço no processo de ensino e aprendizagem para os professores. Os discursos que emergiram da análise nos apresentam algumas reflexões, que sintetizamos a seguir.

Um fato determinante vincula-se a necessidade e importância da formação continuada dos professores, inclusive com reuniões pedagógicas regulares na própria instituição de ensino. Os docentes possuem seus conhecimentos constituídos no seu fazer pedagógico, mas é fundamental que estes fazeres saberes possam ser compartilhados. Qualquer processo de modificação da estrutura de ensino, necessita tempo para implementação, sem este tempo e com a necessidade de adaptar todas as mudanças em curto prazo, a resistência por parte dos docentes certamente se instala.

Com relação aos instrumentos de avaliação, para além da flexibilidade, precisa-se também considerar que a proposta de avaliação para o EMP acarreta mudanças que não podem simplesmente serem abordadas como uma conversão de notas aritméticas para conceitos. Em vista dos discursos que 
apresentamos, podemos observar que o professor ainda requer um tempo maior para realizar seu planejamento e também a avaliação.

Os professores apresentam opiniões distintas no que se refere à avaliação diagnóstica, formativa e cumulativa. O sistema e suas normas impostas sem as devidas condições e estrutura adequada para travar os debates, sem tempo real para a formação continuada é o que impede para que mais avanços ocorram. É necessário levar em conta o que os professores sabem sobre a temática antes de mudar metodologias, instrumentos avaliativos e suas representações.

A avaliação educacional necessita ser vista como um processo integrado que considera todos os sujeitos participantes em seus direitos e deveres e, como participantes ativos e protagonistas do ensino e da aprendizagem.

Sendo assim, a pesquisa a qual trata este artigo demonstra relevância no momento em que contribui para a reflexão sobre a ação pedagógica onde temos a avaliação como um dos temas mais debatidos e polêmicos nas instituições de ensino. Proporcionar esta reflexão e, ao mesmo tempo, trazer à tona as vivências dos educadores, sejam eles docentes ou gestores, demonstra a importância do trabalho, haja vista o alcance que sua divulgação terá na esfera educacional.

\section{REFERÊNCIAS}

BEDIN, Everton \& DEL PINO, José Claudio. Um Estudo sobre a Avaliação no Ensino Médio Politécnico: abordando a questão emancipatória para qualificação dos processos de ensino e aprendizagem. Meta: Avaliação: Rio de Janeiro, v. 7, n. 21, p. 382-402, set./dez, 2015.

BRASIL. Ministério de Educação. Conselho Nacional de Educação. Câmara de Educação Básica. Resolução no 2/2012:Define Diretrizes Curriculares Nacionais para o Ensino Médio. Brasília:CNE, 30 jan. 2012.

BRASIL. Secretaria de Educação Básica. Formação de professores do ensino médio, etapa I - caderno VI: Avaliação no Ensino Médio / Ministério da Educação, Secretaria de Educação Básica; [autores: Ocimar Alavarse, Gabriel Gabrowski]. - Curitiba: UFPR/Setor de Educação, 2013.

FREIRE, Paulo. Pedagogia da Autonomia. SP:Paz e Terra, 1997

HOFLING, Eloisa. Matos. Estado e políticas (públicas) sociais. Cad. CEDES [online]. 2001, vol.21, n.55, pp.30-41. ISSN 0101-3262. Disponível em: < http://dx.doi.org/10.1590/S010132622001000300003 >. Acesso em: 10 de jul.2016.

LEFÉVRE, Fernando; LEFÉVRE, Ana Maria Cavalcanti. Discurso do sujeito coletivo: um novo enfoque em pesquisa qualitativa (desdobramentos). 2ed. Caxias do Sul, RS: Educs, 2005.

MARCONI, Maria de Andrade: LAKATOS, Eva Maria. Fundamentos da metodologia científica. SãoPaulo: Atlas, 2007.

MORETO, Vasco Pedro. Prova: um momento privilegiado de estudos, não um acerto de contas. 9. ed. Rio de Janeiro: Lamparina, 2010.

NOGUEIRA, Nilbo Ribeiro. Pedagogia dos projetos. 2 ed. São Paulo: Érica, 2001.

RAPHAEL, Hélia Sônia. Avaliação: questão técnica ou política? Estudos em Avaliação Educacional, São Paulo, n. 12, p. 33-43, jul./dez. 1995. 
ROMÃO, José Eustáquio. Avaliação: exclusão ou inclusão? EccoS Revista Científica, vol.4, n.1, junho, 2002, pp. 43-59. São Paulo: Universidade Nove de Julho.

SANTIAGO, Anna Rosa F. Epistemologia e avaliação: aproximações curriculares no cotidiano escolar. In: PORTO, Yeda (Org.). Projeto Político-pedagógico: Construindo identidades. Pelotas, RS: Educat, 2001.

SAUL, Ana Maria. Referenciais Freireanos para a Prática da Avaliação. Revista da Educação PUCCampinas. SP: Campinas, n.25, p.17-24, novembro, 2008.

TARDIF, Maurice. Saberes docentes e formação profissional. 17ed. SP: Vozes, 2014.

TRIVIÑOS, Augusto N. S. Introdução à Pesquisa em Ciências Sociais: a Pesquisa Qualitativa em Educação. São Paulo: Atlas, 1987. 